08

\title{
Магнитоупругие волны в субмикронных пленках ЖИГ, полученных ионно-лучевым распылением на подложках гадолиний-галлиевого граната
}

\author{
(С) Ю.В. Хивинцев, ${ }^{1,2}$ В.К. Сахаров, ${ }^{1}$ С.Л. Высоцкий, ${ }^{1,2}$ Ю.А. Филимонов, ${ }^{1-3,}$ Ф А.И. Стогний, ${ }^{4}$ С.А. Никитов ${ }^{5,2}$ \\ ${ }^{1}$ Саратовский фрилиал ИРЭ им. В.А. Котельникова РАН, \\ 410019 Саратов, Россия \\ ${ }^{2}$ Саратовский государственный университет им. Н.Г. Чернышевского, \\ 410026 Саратов, Россия \\ ${ }^{3}$ Саратовский государственный технический университет им. Ю.А. Гагарина, \\ 410054 Саратов, Россия \\ ${ }^{4}$ Научно-практический центр по материаловедению НАН Беларуси, \\ 220072 Минск, Беларусь \\ ${ }^{5}$ Институт радиотехники и электроники им. В.А. Котельникова РАН, \\ 125009 Москва, Россия \\ ฯ e-mail: yuri.a.filimonov@gmail.com
}

(Поступило в Редакцию 2 августа 2017г.)

\begin{abstract}
Обнаружены серии эквидистантных осцилляций в спектре передачи и законе дисперсии поверхностных магнитостатических волн (ПМСВ) Дэймона-Эшбаха, распространяющихся в субмикронных $(200 \mathrm{~nm})$ пленках железоиттриевого граната (ЖИГ), полученных ионно-лучевым распылением на подложках гадолинийгаллиевого граната (ГГГ). Указанные осцилляции отвечают возбуждению магнитоупругих волн в структуре ЖИГ-ГГГ на частотах резонансного взаимодействия ПМСВ с упругими сдвиговыми модами волноведущей структуры ЖИГ-ГГГ. Полученные результаты указывают, что исследованные пленки ЖИГ характеризуются эффективной магнитоупругой связью спиновой и упругой подсистем и согласованием акустических импедансов на интерфейсе ЖИГ-ГГГ, что позволяет рассматривать технологию ионно-лучевого распыления пленок ЖИГ на подложках ГГГ, как перспективную для создания устройств магноники и стрейнтроники.
\end{abstract}

DOI: $10.21883 / J T F .2018 .07 .46178 .2448$

Перспективы интеграции устройств магноники [1,2] с полупроводниковыми электронными компонентами, а также создания монолитных композитных мультиферроидных структур для устройств стрейнтроники $[3,4]$ стимулируют разработку нежидкофазных технологий получения пленок железоиттриевого граната (ЖИГ). На сегодняшний день наиболее широко используются методы импульсного лазерного напыления [5-7], ВЧ магнетронного распыления $[8,9]$ и ионно-лучевого испарения [10-12]. Сообщалось также о получении пленок ЖИГ с использованием золь-гель технологий [13], молекулярно-лучевой эпитаксии [14] и осаждения из газовой фазы [15]. Достигнутый за последние годы прогресс в развитии таких технологий позволяет получать пленки ЖИГ нанометровых $(5-100 \mathrm{~nm})$ и субмикронных $(100-1000 \mathrm{~nm})$ толщин на подложках гадолинийгаллиевого граната (ГГГ) [5-10], Si [10,11], GaN [12]. При этом в таких пленках удается наблюдать распространение субмикронных [7,10] и нанометровых [5] спиновых волн, которые демонстрируют эффекты невзаимности [16], параметрической неустойчивости [17] и позволяют осуществлять эффективный спиновый транспорт $[6-8,15]$. Однако об обнаружении эффектов распространения магнитоупругих волн (МУВ) в структурах ЖИГ/ГГГ, полученных нежидкофазной эпитаксией, до сих пор не сообщалось. В настоящей работе исследовано распространение МУВ в субмикронных пленках ЖИГ, полученных ионно-лучевым распылением на подложках ГГГ.

Отметим, что применительно к эпитаксиальным структурам ЖИГ/ГГГ эффекты распространения МУВ изучены достаточно подробно [18-21]. Показано, что на частотах фазового синхронизма спиновых и упругих волн, поддерживаемых волноведущей структурой ЖИГ/ГГГ, в амплитудно-частотной характеристике (АЧХ) и законе дисперсии спиновой [18-20] или упругой [21] волны, прошедшей через структуру, наблюдаются осцилляции. Мы покажем, что аналогичные особенности наблюдаются в спектре передачи и законе дисперсии поверхностных магнитостатических волн (ПМСВ) Дэймона-Эшбаха при распространении в субмикронных пленках ЖИГ, полученных ионно-лучевым распылением на подложках ГГГ.

В экспериментах использовалась пленка ЖИГ толщиной $d \approx 200 \mathrm{~nm}$, полученная ионно-лучевым распылением на подложке ГГГ с кристаллографической ориентацией $(111)$ и толщиной $D \approx 600 \mu \mathrm{m}$. Пленки выращивались по технологии, описанной в работе [22]. Использовались компактированные мишени керамики состава $\mathrm{Y}_{3} \mathrm{Fe}_{5} \mathrm{O}_{12}$, которые распылялись пучком ионов кислорода с энергией $1600 \mathrm{eV}$ и плотностью тока $\approx 0.25 \mathrm{~mA} / \mathrm{cm}^{2}$ при рабочем давлении кислорода менее $0.4 \mathrm{~Pa}$ и предель- 
ном вакууме $\leq 0.03 \mathrm{~Pa}$. Для обеспечения соответствия катионного состава мишени и осаждаемого материала мишень предварительно распылялась в указанных режимах на сменяемую заслонку в течение $180 \mathrm{~min}$. Поток распыляемого материала при комнатной температуре осаждался на подложку со скоростью $\approx 2.4 \mathrm{~nm} / \mathrm{min}$ и с неравномерностью по поверхности $<10 \%$. Далее образец отжигался на воздухе в течение $60 \mathrm{~min}$ при температуре $850^{\circ} \mathrm{C}$ и равномерно охлаждался до $400^{\circ} \mathrm{C}$ в течение $300 \mathrm{~min}$. На вставках $a-c$ к рис. 1 приведены соответственно изображение поперечного сечения пленки, полученное с помощью атомно-силовой микроскопии (AСM) изображение участка поверхности $2.5 \times 2.5 \mu \mathrm{m}$ пленки ЖИГ, дифрактограмма, измеренная на установке Дрон-4 с фокусировкой по плоскому образцу в геометрии Брэгга-Брентано (схема $\theta-2 \theta \mathrm{Cu} K_{\alpha^{-}}$ излучение, $\lambda \approx 0.15418 \mathrm{~nm})$. Из вставки $a$ можно видеть, что пленка характеризуется плоскопараллельными интерфейсными границами пленка-подложка и пленкаповерхность (здесь над поверхностью ЖИГ показан технологический слой платины, который применяется в стандартной методике изготовления поперечного сечения диэлектрических образцов методом реза фокусированными ионными пучками на станции FIB Helios NanoLab 600). При этом отсутствует видимое размытие интерфейсной области пленка-подложка, которое могло бы быть вызвано диффузионными процессами при отжиге. Поперечное сечение демонстрирует, что пленка имеет толщину $d \approx 200 \mathrm{~nm}$ и является сплошной и однородной. Последнее несколько контрастирует с АСМ изображением поверхности пленки на вставке $b$, где виден гранулированный характер пленки с размером зерна $\approx 200 \mathrm{~nm}$ и перепадами высот $\approx 80 \mathrm{~nm}$. Из дифрактограммы на вставке $c$ видно совпадение рефлексов (888) от пленки и подложки с точностью расхождения их положений $\Delta \theta<0.25^{\circ}$ в окрестности угла отражения $2 \theta \approx 119^{\circ}$, что свидетельствует об эпитаксиальном согласовании кристаллических решеток подложки и пленки и о доминировании текстуры (111) в пленке ЖИГ.

Эффективная намагниченность пленки $4 \pi \mathrm{M}$ определялась из спектров ферромагнитного резонанса (ФМР), измеренных для образца размером $3 \times 3 \mathrm{~mm}$ на частоте $f_{r} \approx 9.9 \mathrm{GHz}$ при углах $\psi$ между направлением магнитного поля Н и плоскостью пленки $\psi \approx 0$ и $\psi \approx 90^{\circ}$ (см. вставку $d$ к рис. 1). Как при перпендикулярном намагничивании $\left(\psi \approx 90^{\circ}\right)$, так и при касательном $(\psi \approx 0)$ в спектре наблюдалось несколько линий поглощения шириной $\Delta H\left(f_{r}\right) \approx 20 \mathrm{Oe}$, что указывает на возбуждение мод спин-волнового резонанса в пленке и отражает неоднородность распределения ее магнитных параметров. Расчет намагниченности, выполненный для основного пика поглощения, дал значение $4 \pi \mathrm{M} \approx 1.733 \mathrm{kgf}$. Отметим, что зависимость резонансных полей $\left|\mathbf{H}_{r}(\varphi)\right|$ в спектре ФМР пленки, намагниченной под углом к нормали $\left(\psi \approx 30-70^{\circ}\right)$ от поворота пленки на угол $\varphi$ относительно направления проекции магнитного поля $\mathbf{H}$ на плоскость пленки, имела период, близкий к $120^{\circ}: H_{r}(\varphi)=H_{r}(\varphi+2 \pi n / 3)$, что является типичным [23] для монокристаллических пленок ЖИГ кристаллографической ориентации (111), выращенных жидкофазной эпитаксией на ГГГ(111). Это позволяет утверждать, что в исследуемой пленке ЖИГ внутреннее эффективное магнитное поле содержит вклад со стороны полей кубической кристаллографической анизотропии. Следовательно, в исследуемой пленке ЖИГ присутствует значительная доля монокристаллической фазы, что согласуется с видом дифрактограммы на вставке $c$ к рис. 1.

Для изучения эффектов распространения спиновых волн на поверхности пленки ЖИГ формировались возбуждающие и приемные антенны в виде закороченных копланарных волноводов из меди по технологии, аналогичной [24]. Антенны имели длину $l \approx 200 \mu \mathrm{m}$, ширину $w$ сигнального и земляных проводников $w \approx 7 \mu \mathrm{m}$, расстояние $j$ между проводниками $j \approx 4 \mu \mathrm{m}$. Исследовались макеты с расстоянием $L$ между сигнальными линиями $L_{1} \approx 50$ и $L_{2} \approx 100 \mu \mathrm{m}$ (рис. 1). Касательное магнитное поле $H \approx 120-1400$ Ое прикладывалось вдоль микроантенн, что соответствовало возбуждению поверхностных магнитостатических волн (ПМСВ) Деймона-Эшбаха [25] в интервале частот $f \approx 1.5-6 \mathrm{GHz}$.

Измерение $S$-параметров макетов линии задержки на ПМСВ проводилось с помощью зондовой станции, векторного анализатора цепей Agilent Technologies E5071 и предусилителя Agilent Technologies 87405C, который использовался для усиления выходного сигнала. Измерениям предшествовала калибровка для исключения влияния зондов, кабелей и предусилителя. Для исключения влияния на результаты измерений электромагнитной наводки проводилось вычитание ее сигнала при $H \approx 2150$ Ое, когда спиновые волны на частотах $<6 \mathrm{GHz}$ не возбуждались. Измерения выполнялись при уровне падающей мощности $P_{\text {in }} \approx-30 \mathrm{dBm}$, что было меньше порогового уровня развития параметрической неустойчивости ПМСВ в исследованных пленках.

На рис. 2 и 3 приведены соответственно частотные зависимости параметра $S_{21}(f)$ и дисперсионные характеристики ПМСВ $f=f(k)$, где волновые числа $k=k(f)$ рассчитывались по результатам измерений набега фазы волны $\theta(f, L)$ в макете с $L_{1} \approx 50 \mu \mathrm{m} \mathrm{c}$ помощью соотношения [26] $k(f)=\theta(f) / L$. На вставках к рис. 2 и $3, b$ показаны в увеличенном масштабе выделенные кружками участки частотной зависимости амплитуды коэффициента прохождения $S_{21}(f)$ ПМСВ и дисперсионных кривых $f=f(k)$ соответственно. Видно, что в зависимости $S_{21}(f)$ наблюдаются эквидистантные осцилляции, разделенные частотными интервалами $\Delta f \approx 3 \mathrm{MGz}$ и имеющие резонансный характер - ширина пика $\leq 1 \mathrm{MGz}$. Глубина осцилляций $\Delta A$ в зависимости $S_{21}(f)$ увеличивалась с расстоянием, что видно из сравнения вставок $a$ и $b$ к рис. 2. При этом в дисперсионной зависимости ПМСВ на резонансных частотах формируются аномальные участки (рис. $3, b$ ). Ранее аналогичные 


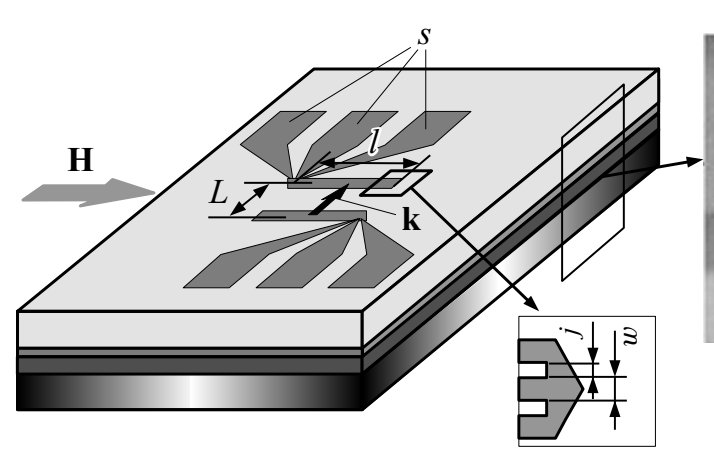

$a$
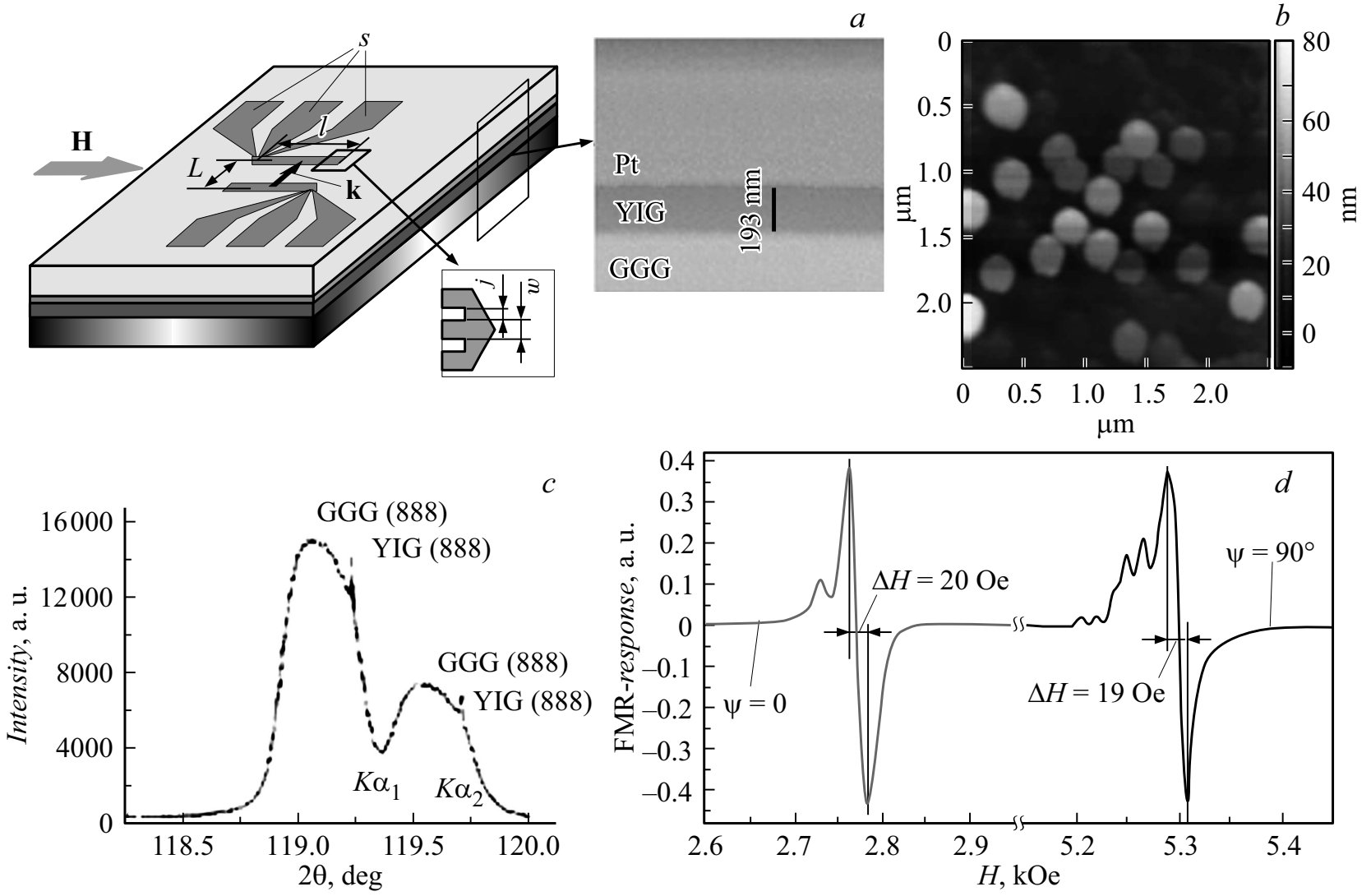

Рис. 1. Вид экспериментального макета, с обозначением параметров копланарных антенн: $L-$ расстояние между центральными проводниками, $w$ - ширина микрополосок, $j$ - расстояние между микрополосками, $s$ - контактные площадки для микрозондов. На вставках: $a$ - изображение скола пленки по толщине, полученное на сканирующем электронном микроскопе; $b-\mathrm{ACM}$ изображение участка $2.5 \times 2.5 \mu$ m поверхности пленки ЖИГ; $c$ - дифрактограмма пленки; $d-$ спектры ФМР при касательном $(\psi \approx 0)$ и нормальном $\left(\psi \approx 90^{\circ}\right)$ намагничивании образца.
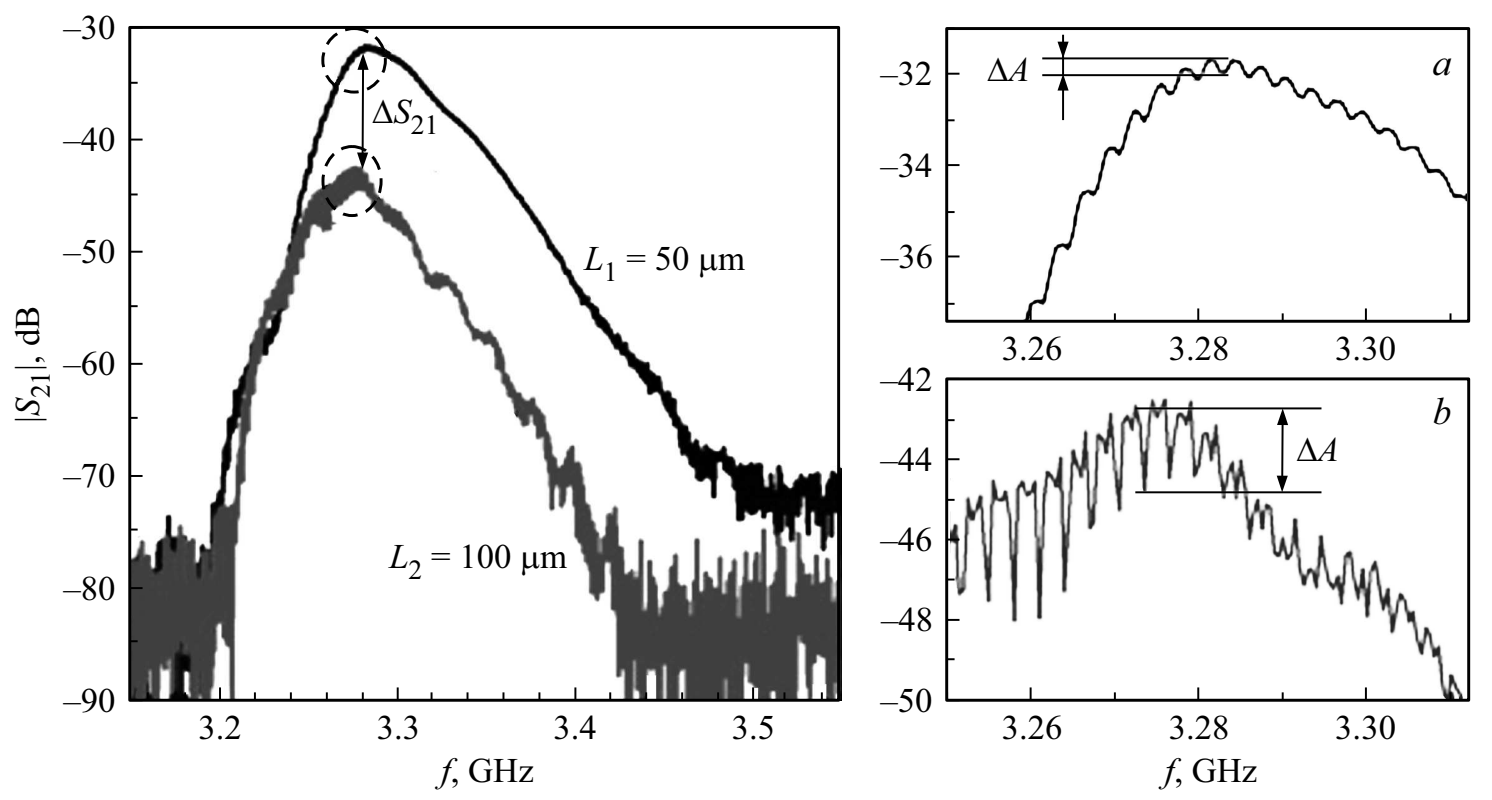

Рис. 2. Спектры коэффициента передачи $S_{21}(f, L)$ ПМСВ в структуре ЖИГ $(200 \mathrm{~nm}) / Г Г Г(600 \mu \mathrm{m})$ при $L_{1} \approx 50 \mu \mathrm{m}$ и $L_{2} \approx 100 \mu \mathrm{m}$ поле $H \approx 550$ Ое. На вставках - увеличенные участки спектра $S_{21}(f, L)$ при $L_{1}(a)$ и $L_{2}(b)$, выделенные кружками. 

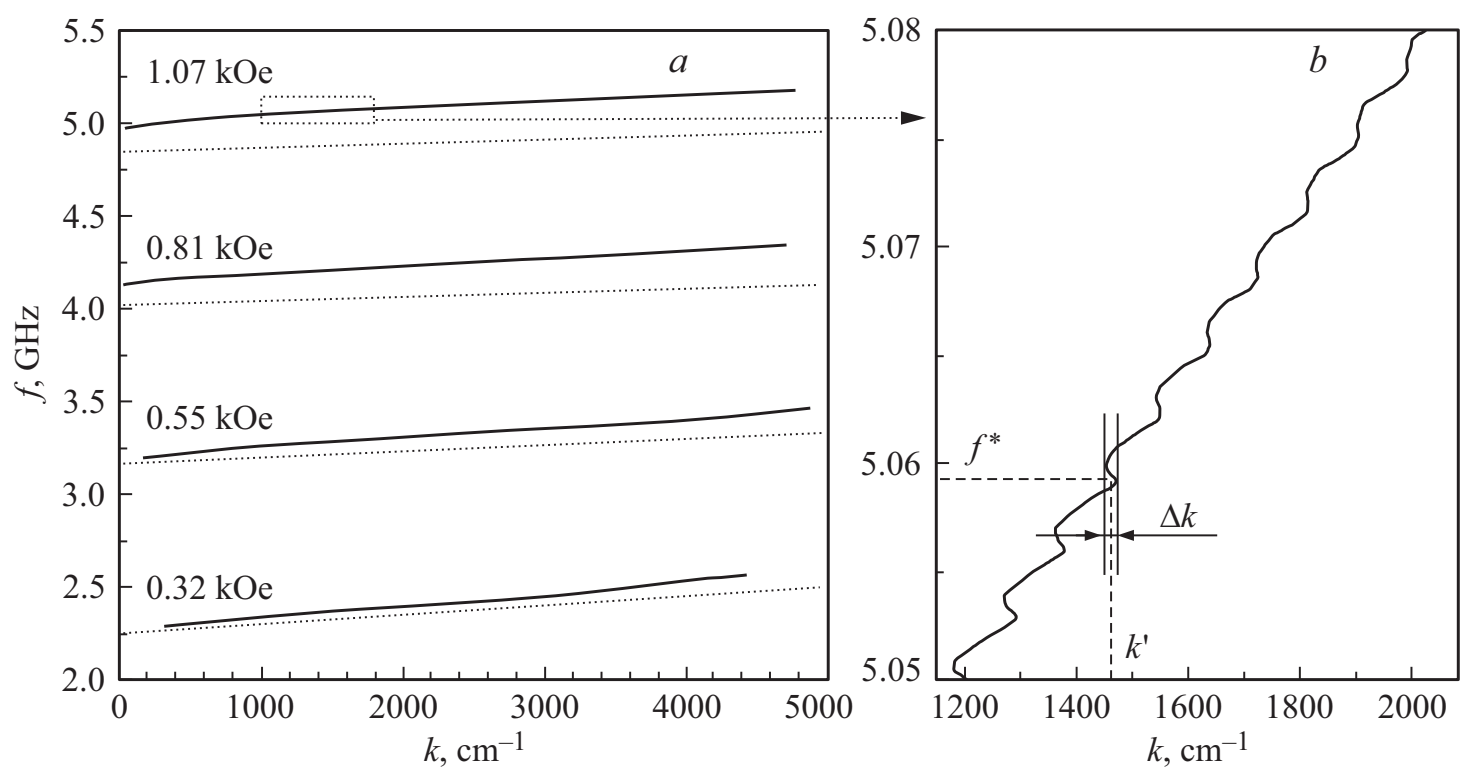

Рис. 3. $a-$ измеренные (сплошные линии) и рассчитанные в дипольном приближении законы дисперсии ПМСВ (пунктир) при полях $H=0.32,0.55,0.81,1.07 \mathrm{kOe}$. Кружками выделены частоты, для которых приведены данные в таблице. $b-$ участок дисперсии, выделенный штриховой линией на дисперсионной кривой при поле $H=1.07 \mathrm{kOe}$, на котором видны аномальные участки в законе дисперсии.

особенности в зависимостях $S_{21}(f)$ и $f=f(k)$ наблюдались в экспериментах по изучению распространения МСВ в эпитаксиальных пленках ЖИГ [18-20], в том числе и в пленках субмикронной толщины $d \approx 0.54 \mu \mathrm{m}[20]$, и связывались с образованием „быстрых“ [27] МУВ на частотах фазового синхронизма МСВ и упругих волн акустического волновода пленка ЖИГ-подложка ГГГ. Поэтому следовало ожидать, что обнаруженные нами резонансные особенности в зависимостях $S_{21}(f)$ и $f=f(k)$ имеют аналогичную природу.

Действительно, резонансные частоты, на которых наблюдаются осцилляции в зависимостях $S_{21}(f)$ и $f=f(k)$, отвечают частотам отсечки сдвиговых упругих мод волноведущей структуры пленка-подложка, которые в случае $d \ll D$ определяются соотношением

$$
f_{N} \approx V_{t} N /(2 D)
$$

где $V_{t}=3.57 \cdot 10^{5} \mathrm{~cm} / \mathrm{s}$ - скорость поперечных акустических волн в ГГГ, $D \approx 600 \mu \mathrm{m}$ толщина ГГГ, $N$ отвечает целому числу полуволн акустической сдвиговой волны по толщине структуры и в случае, показанном на вставке, $N=1092-1102$. При этом частотный интервал между соседними модами с номерами $N$ и $N+1$ определяется как

$$
\Delta f_{N, N+1}=V_{t} /(2 D),
$$

что в нашем случае составляет $\Delta f_{N, N+1} \approx 2.98 \mathrm{MHz}$ и хорошо согласуется с измеренными значениями $\Delta f \approx 3 \mathrm{MHz}$.

В качестве параметров, характеризующих эффективность резонансного взаимодействия спиновой и упругой волн, можно рассматривать „глубину“ осцилляций $\Delta A$ в зависимости $S_{21}(f)$ (вставки к рис. 2) и относительную величину изменений волнового числа $\Delta k / k$ в законе дисперсии $f=f(k)$ (рис. $3, b)$. Отметим, что в пренебрежении влиянием прямой электромагнитной наводки между преобразователями амплитуду осцилляций $\Delta A$ в спектре передачи $S_{21}(f)$ и вызванную резонансным взаимодействием с упругой волновой добавкой $\Delta k_{\mathrm{MEV}}^{\prime \prime}$ к мнимой части $k^{\prime \prime}$ волнового числа ПМСВ $k=k^{\prime}+i k^{\prime \prime}$ можно связать с помощью соотношения $[28,19]$

$$
\Delta A \mathrm{~dB}=-8.68 \Delta k_{\mathrm{MEV}}^{\prime \prime} L,
$$

где $L-$ пройденное волной расстояние. Применимость (3) к нашему случаю подтверждается ростом с расстоянием $L$ „глубины“ осцилляций $\Delta A$ в зависимости $S_{21}(f, L)$, показанных на вставках $(a)$ и $(b)$ на рис. 2.

Для оценки пространственных декрементов ПМСВ как вне частот магнитоупругих резонансов $k^{\prime \prime}$, так и на резонансных частотах $k_{\mathrm{MEV}}^{\prime \prime}=k^{\prime \prime}+\Delta k_{\mathrm{MEV}}^{\prime \prime}$ воспользуемся результатами измерений частотных зависимостей $S_{21}(f)$ в макетах с различными расстояниями между преобразователями $L_{1} \approx 50 \mu \mathrm{m}$ и $L_{2} \approx 100 \mu \mathrm{m}$ (рис. 2). При этом будем обращаться к частотам $f^{*}$, отвечающим максимуму прошедшего сигнала ПМСВ при фиксированном поле подмагничивания. Такие частоты выделены кружками на зависимостях $S_{21}(f)$ и $f=f(k)$ на рис. 2 и 3. В приближении идентичности параметров как преобразователей, так и участков пленки, на которых они размещены, на выбранной частоте $f^{*}$ изменение амплитуды прошедшего сигнала $\Delta A\left(f^{*}\right)=S_{21}\left(f^{*}, L_{1}\right)-S_{21}\left(f^{*}, L_{2}\right)=8.68 k^{\prime \prime} L \mathrm{~dB}$, где $L=L_{2}-L_{1}=50 \mu \mathrm{m}$. В таблице приведены значения 
Значения пространственных декрементов $k^{\prime \prime}, k_{\mathrm{MEV}}^{\prime \prime}, \Delta k_{\mathrm{MEV}}^{\prime \prime}$, а также относительное изменение волнового числа $\Delta k / k$ на частоте магнитоупругого резонанса и групповая скорость $V_{g}$ ПМСВ в рассматриваемой структуре при выбранных значениях поля подмагничивания $H_{1,2,3}$ и частот $f^{*}$

\begin{tabular}{|c|c|c|c|c|c|c|}
\hline$H, f^{*}$ & $k^{\prime \prime}, 1 / \mathrm{cm}$ & $k_{\mathrm{MEV}}^{\prime \prime}, 1 / \mathrm{cm}$ & $\Delta k_{\mathrm{MEV}}^{\prime \prime}, 1 / \mathrm{cm}$ & $\Delta k / k, \%$ & $V_{g}, 10^{5} \mathrm{~cm} / \mathrm{s}$ & $\begin{array}{c}\tilde{k}^{\prime \prime}, 1 / \mathrm{cm} \\
\Delta H\left(f^{*}\right), \text { Oe }\end{array}$ \\
\hline $\begin{array}{l}H_{1} \approx 320 \mathrm{Oe} \\
f^{*} \approx 2.387 \mathrm{GHz}\end{array}$ & 134 & 143 & 9 & $<1$ & 3.7 & $\begin{array}{l}250 \\
2.8\end{array}$ \\
\hline $\begin{aligned} H_{2} & \approx 550 \mathrm{Oe} \\
f^{*} & \approx 3285 \mathrm{GHz}\end{aligned}$ & 270 & 309 & 39 & $<2$ & 3.2 & $\begin{array}{c}330 \\
49\end{array}$ \\
\hline $\begin{array}{l}H_{3} \approx 810 \mathrm{Oe} \\
f^{*} \approx 4.196 \mathrm{GHz}\end{array}$ & 403 & 696 & 293 & $4-10$ & 2.6 & $\begin{array}{c}676 \\
5.9\end{array}$ \\
\hline
\end{tabular}

Примечание. В крайнем правом столбце оценки магнитных потерь ПМСВ $\tilde{k}^{\prime \prime} \approx \gamma \Delta H\left(f^{*}\right) / V_{g}$, где значения $\Delta H\left(f^{*}\right)=\Delta H\left(f_{r}\right) \cdot f^{*} / f_{r}$ учитывают зависимость скорости релаксации спиновых волн от частоты, а также эффективная ширина линии $\Phi$ ФР $\left(\widehat{\Delta H(f *)} \approx k^{\prime \prime} V_{g} / \gamma\right.$, где значения $k^{\prime \prime}$ и $V_{g}$ берутся из таблицы.

$k^{\prime \prime}, k_{\mathrm{MEV}}^{\prime \prime}, \Delta k_{\mathrm{MEV}}^{\prime \prime}$, рассчитанные с помощью соотношения (3), и $\Delta k / k$, рассчитанные по результатам измерения фазочастотных характеристик, для значений поля $H_{1} \approx 320 \mathrm{Oe}, H_{2} \approx 550$ Ое и $H_{3} \approx 810$ Ое. Здесь же для сравнения приведены оценки величин $\left(\tilde{k}^{\prime \prime}\right)$ для дипольных ПМСВ (вне частот (1)), полученные с помощью соотношения $\tilde{k}^{\prime \prime} \approx \gamma \Delta H\left(f^{*}\right) / V_{g}$, где $\gamma=1.76 \cdot 10^{7} \mathrm{Oe}^{-1} \cdot \mathrm{s}^{-1}$ - гиромагнитное отношение для ЖИГ, $V_{g}$ - групповая скорость ПМСВ, рассчитанная для выбранных частот по наклону дисперсионных зависимостей на рис. 3, $a$, а значение ширины линии ФМР на частоте $f^{*}$ пересчитывается с учетом линейной зависимости скорости релаксации спиновых волн от частоты $\Delta H\left(f^{*}\right)=\Delta H\left(f_{r}\right) f^{*} / f_{r}$.

Из таблицы видно, что с ростом поля (частоты $f^{*}$ ) вызванные резонансным взаимодействием с упругим волнами добавки в дисперсию $\Delta k / k$ и затухание $\Delta k_{\mathrm{MEV}}^{\prime}$ резко увеличиваются. Параметр $\Delta k / k$ возрастает от значений $\leq 1 \%$ при $H_{1} \approx 320 \mathrm{Oe}\left(f^{*} \approx 2.387 \mathrm{GHz}\right)$ до $4-10 \%$ при $H_{3} \approx 810 \mathrm{Oe}\left(f^{*} \approx 4.195 \mathrm{GHz}\right)$. Для потерь изменения еще контрастнее. Действительно, если при поле $H_{1} \approx 320 \mathrm{Oe}\left(f^{*} \approx 2.387 \mathrm{GHz}\right)$ значения $\Delta k_{\mathrm{MEV}}^{\prime} \approx 9 \mathrm{~cm}^{-1}$ и на порядок меньше измеренных значений пространственного декремента $k^{\prime \prime} \approx 133 \mathrm{~cm}^{-1}$, то при $H_{3} \approx 810 \mathrm{Oe}\left(f^{*} \approx 4.195 \mathrm{GHz}\right)$ магнитоупругое взаимодействие приводит на полтора порядка большим значениям $\Delta k_{\mathrm{MEV}}^{\prime \prime} \approx 290 \mathrm{~cm}^{-1}$, что всего лишь на $30 \%$ меньше значений магнитных потерь $k^{\prime \prime} \approx 403 \mathrm{~cm}^{-1}$. То

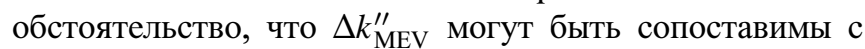
магнитными потерями $\left(\Delta k_{\mathrm{MEV}}^{\prime \prime} \approx k^{\prime \prime}\right)$ и даже существенно их превышать $\left(\Delta k_{\mathrm{MEV}}^{\prime \prime} \gg k^{\prime \prime}\right)$, хорошо известно для „быстрых“ МУВ $[28,19]$ и объясняется большими потерями упругих волн на распространение вдоль волновода ЖИГ-ГГГ на резонансных частотах (1).

Обращает на себя внимание рост эффективности взаимодействия ПМСВ и УВ с частотой (см. таблицу). Этот факт следует связать с двумя обстоятельствами, определяющими эффективность возбуждения звука в структуре ЖИГ-ГГГ [29-31]. С одной сто- роны, указанная эффективность пропорциональна интегралу $I$ перекрытия намагниченности ПМСВ $\mathbf{m}$ и магнитострикционного поля $\left(\mathbf{h}_{m e}\right)$ упругой волны по толщине пленки ЖИГ $I \sim \int_{0}^{d} \mathbf{m h}_{m e} d z$. С другой стороны, наибольшая эффективность перекачки звука из пленки ЖИГ в подложку ГГГ будет достигаться при согласовании акустических импедансов $Z=\rho V_{t}(\rho-$ плотность среды) на интерфейсе: $\rho_{\mathrm{YIG}} V_{\mathrm{YIG}}=\rho_{\mathrm{GGG}} V_{\mathrm{GGG}}$. Если считать, что исследуемая структура ЖИГ/ГГГ имеет упругие параметры, близкие к монокристаллическим эпитаксиальным структурам [29]: $\rho_{\text {YIG }} \approx 5.17 \mathrm{~g} / \mathrm{cm}^{3}$, $V_{\mathrm{IYG}} \approx 3.85 \cdot 10^{5} \mathrm{~cm} / \mathrm{s}, \rho_{\mathrm{GGG}} \approx 7.02 \mathrm{~g} / \mathrm{cm}^{3}, V_{\mathrm{GGG}}=V_{t}$, то получим $Z_{\mathrm{IYG}} \approx 0.8 Z_{\mathrm{GGG}}$, что отражает хорошее согласование импедансов [30,31]. В этом случае эффективному возбуждению упругих волн в структуре будет отвечать частота $f_{\max } \approx V_{\mathrm{IYG}} /(2 d) \approx 9.6 \mathrm{GHz}$. В нашем случае мы не смогли пронаблюдать распространение ПМСВ на частотах выше $6 \mathrm{GHz}$ из-за падения амплитуды выходного сигнала и невозможности его выделения на уровне шумов. Однако тенденция к нарастанию эффективности взаимодействия ПМСВ и сдвиговых упругих волн в структуре ЖИГ/ГГГ наблюдается, что подтверждает предположение о хорошем акустическом контакте на границе пленка-подложка в исследуемой структуре.

Отметим, что потери в спиновой и упругой подсистемах разрушают магнитоупругий резонанс [29,32]. Потери упругих волн в нашем случае $(d \ll D)$ определяются в основном подложкой ГГГ и для типичной вязкости звука $\xi$ в гранатах [29] $\xi \approx 3 \cdot 10^{-16} \mathrm{~s}$ на частоте $f=6 \mathrm{GHz}$ временной декремент сдвиговых волн составит $\omega_{e l}^{\prime \prime}=4 \pi^{2} f^{2} \xi \approx 1.4 \cdot 10^{7} \mathrm{~s}^{-1}$. Такие малые потери сдвиговых упругих волн позволяют наблюдать в структурах ЖИГ/ГГГ задержку упругих волн на частоте $3 \mathrm{GHz}$ до $10 \mu \mathrm{s}$ [29]. Потери в магнитной подсистеме в нашем случае, рассчитанные по результатам измерения ширины линии в спектре ФМР (вставка $d$ рис. 1), оказываются $\omega_{m}^{\prime \prime} \approx \gamma \Delta H \approx 3.5 \cdot 10^{8} \mathrm{~s}^{-1}$, что на порядок больше не только потерь в упругой подсистеме, но и типичных значений магнитоупругой щели $\Delta \omega \leq 10^{7} \mathrm{~s}^{-1}$ в 
спектре ПМСВ в структурах ЖИГ/ГГГ [29,33]. При этом оказывается выполненным условие $\left|\omega_{e l}^{\prime \prime}-\omega_{m}^{\prime \prime}\right| \gg \Delta \omega$, что должно приводить к разрушению синхронизма спиновой и упругой волн [33,29]. Чтобы преодолеть противоречие сделанных оценок с результатами эксперимента, следует предположить, что в ширину линии ФМР $\Delta H\left(f_{r}\right) \approx 20$ Ое вносится существенный вклад, обусловленный неоднородностью параметров пленки. Чтобы оценить диссипативную составляющую обратимся к правой колонке таблицы, где приведены значения пространственного декремента ПМСВ $\tilde{k}^{\prime \prime}$, полученные с помощью соотношения $\tilde{k}^{\prime \prime} \approx \gamma \Delta H\left(f^{*}\right) / V_{g}$, где $\Delta H\left(f^{*}\right)=\Delta H\left(f_{r}\right) f^{*} / f_{r}$ учитывает зависимость скорости релаксации спиновых волн от частоты. Видно, что рассчитанные таким образом значения пространственного декремента оказываются на $50-150 \%$ больше по сравнению с измеренными величинами $k^{\prime \prime}$, указанными в левой колонке. С другой стороны, если воспользоваться приведенными в таблице результатами измерений $k^{\prime \prime}$ и $V_{g}$, то можно получить оценку эффективной ширины линии ФМР $\widetilde{\Delta H\left(f^{*}\right)}$ на частоте $f^{*}$ с помощью соотношений [32] $\widetilde{\Delta H\left(f^{*}\right)} \approx k^{\prime \prime} V_{g} / \gamma$. Полученные таким образом значения эффективной ширины линии ФМР $\widetilde{\Delta H\left(f^{*}\right)}$ составляют, например, для частоты $f^{*} \approx 2.387 \mathrm{GHz}$ величину $\widetilde{\Delta H\left(f^{*}\right)} \approx 2.9$ Ое, что в 1.6 раза меньше значений $\Delta H\left(f^{*}\right)$, определенных по результатам измерений ширины линии в спектре ФМР. При этом следует учесть, что неоднородность параметров пленки приведет к расфазировке ПМСВ на выходном преобразователе, что приведет к дополнительному падению уровня $S_{21}\left(f^{*}, L\right)$, как следствие, завышенным потерям ПМСВ, рассчитанным по формуле (3). С учетом сказанного можно утверждать, что для исследованной структуры вклад со стороны неоднородности параметров пленки в результаты измерения ширины линии в спектре ФМР составляет не менее $50 \%$.

\section{Заключение}

Таким образом, исследовано распространение ПМСВ Дэймона-Эшбаха с длинами волн $15-100 \mu \mathrm{m}$ в пленках ЖИГ толщиной $\approx 200 \mathrm{~nm}$, полученных ионно-лучевым распылением на подложках ГГГ (111) толщиной $\approx 600 \mu \mathrm{m}$. Показано, что в диапазоне частот $2-6 \mathrm{GHz}$ в спектре передачи и дисперсионной зависимости ПМСВ таких субмикронных пленок могут наблюдаться серии эквидистантных осцилляций. Указанные осцилляции отвечают возбуждению магнитоупругих волн в структуpe ЖИГ/ГГГ на частотах резонансного взаимодействия ПМСВ с упругими сдвиговыми модами волноведущей структуры ЖИГ-ГГГ. Полученные результаты указывают, что структуры ЖИГ/ГГГ, полученные технологией ионно-лучевого распыления, характеризуются эффективной магнитоупругой связью спиновой и упругой подсистем и согласованием акустических импедансов на интерфейсе ЖИГ-ГГГ. При этом сама технология перспективна для создания устройств магноники и стрейнтроники, а также структур, демонстрирующих акустическую спиновую накачку [34].

Работа выполнена при финансовой поддержке РФФИ (проекты № 16-29-14058, 16-57-00135) и БРФФИ (проект № Ф16Р-085).

\section{Список литературы}

[1] Никитов С.А., Калябин Д.В., Лисенков И.В., Славин А.Н. и др. // УФН. 2015. Т. 185. С. 1099-1128.

[2] Serga A.A., Chumak A.V., Hillebrands B. // J. Phys. D: Appl. Phys. 2010. Vol. 43. P. 264002.

[3] Fetisov Y.K., Srinivasana G. // Appl. Phys. Lett. 2006. Vol. 88. P. 143503.

[4] Устинов А.Б., Фетисов Ю.К., Лебедев С.В., Srinivasan G. // Письма в ЖТФ. 2010. Т. 36. Вып. 4. С. 41-47.

[5] Yu H., d'Allivy-Kelly O., Cros V., Bernard R., Bartolotti P., Anane A., Brandl F., Huber R., Stasinopoulos I., Grundler D. // Sci. Rep. 2014. 4:6848. doi: 10.1038/srep06848

[6] Wang H.L., Du C.H., Pu Y., Adur R., Hammel P.C., Yang F.Y. // Phys. Rev. B. 2013. Vol. 88. P. 100406(R)

[7] Evelt M., Demidov V.E., Bessonov V., Democritov S.O., Prieto J.L., Munoz M., Youseff J. B., Naletov V.V., de Loubens G., Klein O., Collet M., Garcia-Hermandez K., Bortolotti P., Cros V., Anane A. // Appl. Phys. Lett. 2016. Vol. 108. P. 172406.

[8] Lustikova J., Shiomi Y., Qiu Z., Kikkawa T., Iguchi R., Uchida K., Saitoh E. // J. Appl. Phys. 2014. Vol. 116. P. 153902 1-6.

[9] Kang Y.M., Wee S.H., Baik S.I., Min S.G., Yu S.C., Moon S.H., Kim Y.W., Yoo S.I. // J. Appl. Phys. 2005. Vol. 97. P. 10A31913.

[10] Stognij A.I., Lutsev L.V., Bursian V.E., Novitskii. N.N. // J. Appl. Phys. 2015. Vol. 118. P. 023905.

[11] Sakharov V., Khivintsev Y., Vysotsky S., Shadrov V., Stognij A., Filimonov $Y$. // Proc. 20th Int. Conf. Magn. Barcelona, Spain. 2015. P. 1546.

[12] Stognij A., Lutsev L., Novitskii N., Bespalov A., Golikova O., Ketsko V., Gieniusz R., Maziewski A. // J. Phys. D: Appl. Phys. 2015. Vol. 48. N 48. P. 485002-8.

[13] Aldbea F.W., Ahmad N.I., Ibrahim N.B., Yahya M. // J. Sol-Gel Sci. Technol. 2-14. Vol. 71 P. 31-37.

[14] Jermain C.L., Paik H., Aradhya S.V., Buhrman R.A., Schlom D.G., Ralph D.C. // Appl. Phys. Lett. 2016. Vol. 109. P. 192408. doi: 10.1063/1.4967695

[15] Kirihara A., Kajiwara Y., Ishida M., Nakamura Y., Manako T., Saitoh E., Yorozu S. // Nat. Mat. 2012. Vol. 11. P. 686-689.

[16] Sakharov V.K., Khivintsev Y.V., Vysotskii S.L., Stognij A.I., Filimonov Y.A. // IEEE Magn. Lett. 2017. Vol. 8. P. 3704804.

[17] Сахаров В.К., Хивинщев Ю.В., Высочкий С.Л., Стогний А.И., Дудко Г.М., Филимонов Ю.А. // Изв. вузов. Прикладная нелинейная динамика. 2017. Т. 25. № 1. С. 35 51.

[18] Гуляев А., Зильберман П.Е., Казаков Г.Т., Сысоев В.Г., Тихонов В.В., Филимонов Ю.А., Нам Б.П., Хе А.С. // Письма в ЖЭТФ. 1981. Т. 39. № 9. С. 500-504. 
[19] Казаков Г.Т., Тихонов В.В., Зильберман П.Е. // ФТТ. 1983. T. 25. № 8. C. 2307-2312.

[20] Андреев А.С., Зильберман П.Е., Кравченко В.Б., О2рин Ю.Ф., Темирязев А.Г., Филимонова Л.М. // Письма в ЖТФ. 1984. Т. 10. Вып. 2. С. 90-94.

[21] Казаков Г.Т., Котелянский И.М., Маряхин А.В., Филимонов Ю.А., Хивинцев Ю.В. // РЭ. 2004. Т. 49. № 5. С. 568 576.

[22] Stognij A.I., Tokarev V.V., Mitin Yu.N. // Mat. Res. Soc. Symp. Proc. 1992. Vol. 236. P. 331-334.

[23] Дудко Г.М., Казаков Г.Т., Сухарев А.Г., Филимонов Ю.А., Шеин И.В. // РЭ. 1990. Т. 35. № 5. С. 966-976.

[24] Khivintsev Yu.V., Filimonov Yu.A., Nikitov S.A. // Appl. Phys. Lett. 2015. Vol. 106. P. 052407.

[25] Damon R.W., Eshbach J.R. // J. Phys. Chem. Sol. 1961. Vol. 19. P. 308-320. doi: 10.1016/0022-3697(61)90041-5

[26] Schilz W. // Philips Res. Rep. 1973. Vol. 28. P. 50-65.

[27] Бугаев А.С., Гуляев Ю.В., Зильберман П.Е., Филимонов Ю.А. // ФТТ. 1981. Т. 23. Вып. 4. С. 2647-2655.

[28] Бугаев А.С., Гуляев Ю.В., Зильберман П.Е., Филимонов Ю.А. // РЭ. 1982. Т. 27. № 10. С. 1979-1983.

[29] Гуляев Ю.В., Зильберман П.Е. // Изв. вузов. Физика. 1988. T. 31. № 11. С. 6-23.

[30] Ле-Кроу Р., Комсток Р. // Физическая акустика / Под. ред. У. Мэзона. М.: Мир, 1968. Т. 3. Ч. Б. С. 156-243.

[31] Штраус В. Магнитоупругие свойства иттриевого феррита-граната. Физическая акустика / Под. ред. У. Мэзона. М.: Мир, 1970. Т. 4. Ч. Б. С. 247-316.

[32] Ахиезер А.И., Барьяхтар В.Г., Пелетминский С.В. Спиновые волны. М.: Наука, 1967. 368 с.

[33] Филимонов Ю.А., Хивинцев Ю.В. // РЭ. 2002. Т. 47. № 8. C. 1002-1007.

[34] Polzikova N.I., Alekseev S.G., Pyatakin I.L., Kotelyanskii I.M., Luzanov V.A., Orlov A.P. // AIP Advances. 2016. Vol. 6. P. 056306. 